\title{
Characterization of Rhizobia from Root Nodule and Rhizosphere of Lablab purpureus and Vigna sinensis in Bangladesh
}

\author{
Safirun Pervin*, Bushra Jannat, Sohana Al Sanjee, Tasmia Farzana
}

Department of Microbiology, Primeasia University, PO box 1213, Dhaka, Bangladesh

\section{A R T I C LE I N F O}

Received 18 April 2016

Accepted 20 December 2016

Keywords:

Root nodules

Leguminous plant

Rhizobia

Bangladesh

Symbiosis

${ }^{*}$ Corresponding Author:

E-mail: safirunshifa@gmail.com \begin{abstract}
A B S T R A C T
Nitrogen fixation resulting from mutual symbiosis of rhizobia and cultivated legume plants is therefore critical to food security as it directly affects agricultural production. Biological Nitrogen Fixation (BNF) can be an important factor in sustainable agriculture. The isolation and identification of different slow growing and fast growing rhizobial strains from the nodules of two leguminous plant species. Symbiotic nitrogen fixing Rhizobium spp. was isolated from (Lablab purpureus and Vigna sinensis). Nodules samples were collected from plants growing in different Districts of Bangladesh and the Glucose-Peptone Agar (GPA), Congo red, Yeast Mannitol Agar (YMA) containing 2\% $\mathrm{NaCl}$ were employed to make presumptive decisions on the recognition and classification of the isolated bacterial strains. All the isolates were found with poor absorption of dye Congo red and little or no growth on the media of GPA and without altering the $\mathrm{pH}$. Almost all of the isolates exhibit growth on $2 \% \mathrm{NaCl}$, poor growth on GPA, thus confirming the rhizobia. After biochemical tests like catalase test and citrate utilization test isolates were confirmed as Rhizobia. The presence of rhizobia on root nodules of leguminous Plant. Not only the leguminous Plant but also the rhizosphere contains rhizobia which help in soil fertilization.
\end{abstract}

\section{Introduction}

Ecologically and agriculturally leguminous plant is important and this plant possesses a unique ability to establish symbiosis with nitrogen fixing bacteria of the family Rhizobiaceae from the genera Bradyrhizobium, Rhizobium, Allorhizobium, Mesorhizobium and Sinorhizobium (Martínez-Romero, 2003) which are collectively referred as rhizobia, helps in biological nitrogen fixation by formation of root nodules. An efficient source of nitrogen is BNF (Peoples et al., 1995). Within the root nodules, colonization of bacteria occurs and it converts atmospheric nitrogen to ammonia and provides the plants an organic nitrogenous compounds. The soluble form of nitrite and nitrate can be assimilated by plant roots and utilized in synthesizing proteins and nucleic acids. Without these bacteria, within a short time organic matter such as straw or leaves would accumulate and soil would not be fertile (Kummerer, 2004). BNF is on expanded interest of ecology that has drawn attention to the fact that is ecologically benign and its greater occlusion can minimize the use of fossil fuels and can be subsidiary in reforestation and in restoration of misused lands to productivity (Burris, 1994; Sprent et al., 1990). Nitrogenous wastes are returned by the animals to the environment as uric acid (Atlas et al., 1998). The main way of nitrogen is provided to cropping systems in the form of industrially produced nitrogen fertilizers. Use of these fertilizers has led to worldwide ecological problems as well as affects the human health (Virtuosic, 1997). It has been proven that the presence of rhizobia increases plant productivity without any harm to human health. So for maintaining soil fertility, cultivation of leguminous plants is important which replenish atmospheric nitrogen through symbiosis with rhizobia in rotation with non leguminous plants. This study is aimed to isolate and identify rhizobium species from root nodules of Lablab purpureus and Vigna sinensis from the target area of Bangladesh for better agricultural growth.

\section{Material and Methods}

Study Area

This study was conducted in department of microbiology, Primeasia university and samples were collected from different district of Dhaka division in Bangladesh.

\section{Collection of Nodules}

Two different legume plants (Table 1) were collected from rural areas of Bangladesh. Fresh and healthy root nodules were selected from each plant for the present study. The selected nodules were usually light brown or pinkish in color, which indicates that an active nitrogen fixation had been established between the nodule bacteria and the legume plant. Besides collection of nodule from leguminous plant, the rhizospheric soil around the plant was also collected. 
Table 1 List of the sample and their host under investigation

\begin{tabular}{l|c}
\hline Sample designation & Host Scientific name \\
\hline S-1 & Lablab purpureus \\
S-2 & Vigna sinensis \\
\hline
\end{tabular}

\section{Surface Sterilization of the Nodules}

Total fifty (50) samples of root nodules from Lablab purpureus and Vigna sinensis were collected randomly from five different localities of Dhaka city. Nodules were thoroughly washed under tap water and then carefully severed from the root with sterile forceps. Intact, undamaged nodules were immersed in $95 \%$ ethanol for 5 10 second to break the surface tension and then transferred to $3 \%$ solution of $\mathrm{H}_{2} \mathrm{O}_{2}$ and soaked for 2-3 minutes. Nodules were then rinsed in five changes of sterile distilled water using sterile forceps for transferring.

\section{Isolation of Root Nodule Bacteria}

The first step of the isolation process was to crush the sterile nodules with a blunt tipped forceps in a large drop of sterile water in a petri dish. Using yeast extract mannitol selective culture media (YEM) (Handley et al., 1998; Castro et al., 2003; Kucuk et al., 2006) the nitrogen fixing bacteria can be isolated directly from the root nodules of the host plant or from the soil (Geniaux et al., 1993)

\section{Maintenance of Cultures}

The isolates were sub-cultured on YMA slants. Growth was observed at $30^{\circ} \mathrm{C}$ and then the slants were kept at $4^{\circ} \mathrm{C}$. Periodic subcultures from these stock cultures were performed at a 15 days interval. For long time storage, the isolates were streaked on YMA slants and after incubation at the same temperature; sterile glycerol was added on the media and then stored at room temperature.

\section{Morphological Characteristics of the Isolates}

Colony characteristics: The colony characteristics (i.e. shape, size, color, opacity, elevation, edge, margin of the bacterial colony and their growth rate) were determined by observing the colonies on YMA plates after growth at $30^{\circ} \mathrm{C}$. Microscopic Observation of the Isolates was done using Gram staining technique as described by (Arora, 2003).

\section{Cultural and Metabolic Characteristics}

Presumptive tests: Strain of rhizobia can be described according to their growth on the solid and liquid media. The size, shape, color, texture of the colonies and their growth on different media and their ability to alter the $\mathrm{pH}$ of the media are generally stable characteristics useful in defining strains.

Congo red test: The purity of the rhizobial isolates was detected by adding Congo red in YMA media (Somasegaran et al., 1994).Most rhizobia absorb the dye only weakly whereas contaminants including Agrobacteria, will absorb strongly.
Growth on Glucose-peptone agar: Glucose-peptone media was used to differentiate rhizobia, which usually shows little or no growth on the media without altering the $\mathrm{pH}$ of the media, contaminants like Agrobacteria, shows massive growth on the media with a distinct change in $\mathrm{pH}$.

Growth on 2\% NaCl: To the basal medium of YMA, $2 \% \mathrm{NaCl}$ was added to check the purity of the isolates. As $2 \% \mathrm{NaCl}$ is inhibitory for most rhizobial isolates it can serve as an identification tool.

Differentiation between fast and slow growers on the Bromothymol blue media: Yeast Mannitol Agar (YMA) media incorporated with bromothymol blue was used to distinguish fast-(acid producing) growing strains from slow (non acid producing or alkali producing) growing rhizobia (Somasegaran et al., 1994). In this medium, the fast growers require 48 hours to produce an acidic reaction by turning the color of the media yellow from green, whereas the slow growers take $>96$ hours to produce alkaline endpoints with or without changing the color of the media from green to blue.

\section{Biochemical Characteristics}

To confirm whether the isolates were rhizobia or not, they were incubated in different media for each physiochemical tests and then incubated depending upon their growth rate at $30^{\circ} \mathrm{C}$.

Catalase activity test: The presence of the enzyme catalase in the rhizobial isolates was examined by suspending one loopful of organism in a drop of $3 \% \mathrm{H}_{2} \mathrm{O}_{2}$ on a glass slide. This test was performed as per standard procedure (Cappuccino et al., 1992).Production of bubbles indicates a positive result.

Citrate utilization test: Citrate utilization by the isolates was observed by the growth on slants of Simmon's Citrate Agar. A distinct change in color from green to blue refers to as a positive test.

\section{Results}

The present study encompassed the isolation and identification of different slow growing and fast growing rhizobial strain from the nodule of two leguminous plants and from the associated rhizospheres.

\section{Identification and Characterization}

Staining properties: Microscopic observations were performed to investigate the isolate such as shape, Gram reaction. All the isolates were found to be Gram negative, short, rod shaped and are non- sporeforming.

Colony morphology: Growth rate and colony morphology of the isolates were observed. Most of the isolates were found to produce translucent colonies with deep center, entire, convex, and are mucoid.

\section{Cultural and Metabolic Characteristics}

Presumptive tests: The presumptive test was performed for strains to differentiate between fast growing and slow growing strains. The result of presumptive tests are summarized in Table 2. 
Table 2 Presumptive tests results

\begin{tabular}{|c|c|c|c|c|}
\hline Isolates & $\begin{array}{c}\text { Growth on } \\
\text { glucose-peptone agar }\end{array}$ & $\begin{array}{c}\text { Congo red } \\
\text { Test }\end{array}$ & $\begin{array}{l}\text { Growth on } \\
2 \% \mathrm{NaCl}\end{array}$ & $\begin{array}{c}\text { Bromo-thymol } \\
\text { blue test }\end{array}$ \\
\hline Vigna sinensis (nodule) & No growth & Pink colour & No growth & Blue colour \\
\hline & No growth & Pink colour & No growth & Yellow colour \\
\hline Vigna sinensis (rhizosphere) & Little growth & Pink colour & No growth & Yellow colour \\
\hline Lablab purpureus (nodule) & Little growth but no colour change & Pink colour & No growth & Blue colour \\
\hline Lablab purpureus (rhizosphere) & No growth & Pink colour & No growth & Yellow colour \\
\hline
\end{tabular}

Table 3 Biochemical behaviours of the test strains

\begin{tabular}{l|cc}
\hline \multicolumn{1}{c|}{ Isolates } & Catalase test & Citrate utilization test \\
\hline Vigna sinensis (nodule) & + & - \\
Vigna sinensis (rhizosphere) & + & - \\
Lablab purpureus (nodule) & + & - \\
Lablab purpureus (rhizosphere) & + & - \\
\hline
\end{tabular}

All the isolates from rhizosphere acted as fast grower and produced acid but isolates from nodule acted as slow grower in Bromothymol blue. Isolates of Vigna sinensis (rhizosphere) grown on GPA showed little growth or no growth and isolates of Vigna sinensis (nodule) showed no growth on GPA. Isolates of Lablab purpureus (nodule) showed little growth but no colour change and isolates from Lablab purpureus (rhizosphere) showed no growth. In $2 \% \mathrm{NaCl}$ no growth of the isolates was also observed. In congo red all the isolates showed pink colour or absorbed weakly. All the isolates, showed poor absorption of dye Cong red, little or no growth on the media of GPA without altering the $\mathrm{P}^{\mathrm{H}}$. This fact give further evidence for purity of the Rhizobial isolates (Somasegaran et al., 1994). High salt concentrations, like $2 \% \mathrm{NaCl}$, act as an inhibitor for Rhizobial growth, some common bacterial contaminant e.g. Agrobacterium shows considerable growth on similar salt concentration. But almost all of the isolates exhibit growth on $2 \% \mathrm{NaCl}$ which support the investigation carried out by (Dubey et al., 2010). Poor growth on GPA can be explained as such that, rhizobia do not prefer the peptone as a source of nitrogen, vitamin or growth factor or amino acids.

\section{Biochemical Characteristics of the Isolates}

All the isolates were tested for selective biochemical tests which are presented in Table 3 .

Mahana et al. (2000) also reported catalase activity in some isolates from nodules and rhizosphere were catalase positive and citrate negative. So in catalase test bubbles were produced and in citrate test no colour change observed and it remained green.

\section{Discussion}

Bangladesh has made impressive progress in improving the production of rice and other crops during the past few years. However there are still much lacking in nutrition. We are mainly concerned with carbohydrate and protein intake. A vast majority of the poor in Bangladesh cannot afford animal or fish proteins, and thus have to depend on cheap and easily available vegetable protein - mainly pulses and legumes, which are known as "poor man's beef". Research on the rhizobia has revealed a lot about the role of biological nitrogen fixation in the field of agriculture. Rhizobia by diminishing input of the fertilizer in the field and positively influencing plant crop growth, contribute to the development of the sustainable agriculture, which is necessary for the agriculture based, under developed country like Bangladesh. The present study is expected to reveal the diversity of these Rhizobial strains native to Bangladesh, to some extent, especially with the agronomically and ecologically interesting pulse legume. This study showed the presence of rhizobia on root nodules of leguminous Plant. Not only the leguminous Plant but also the rhizosphere contains rhizobia which help in soil fertilization. Further studies are recommended to identify additional characteristics of rhizobia, and to assess biological nitrogen fixation.

\section{Acknowledgements}

We cordially acknowledge the Department of Microbiology, Primeasia University Dhaka, Bangladesh. This Work was supported by Center for Excellence of Microbiology Research, Primeasia University, Bangladesh.

\section{References}

Arora DR. 2003. The Text Book of Microbiology, CBS Publisher, New Delhi, 41-48.

Atlas R, Bartha R. 1998. Microbial Ecology: Fundamentals and Applications, Benjamin CummingsPublisher. Menlo Park, Canada, (4th Ed.), 694.

Burris RH. 1994. Biological nitrogen fixation - past and future, In N. A. Hegazi, M. Fayez, and M. Monib (ed.), Nitrogen fixation with nonlegumes. The American University in Cairo Press, Cairo, Egypt. p: 1-11.

Castro IV, Ferreira EM, McGrat SP. 2003. Survival and plasmid stability of rhizobia introduced into a contaminated soil. Soil Biol. Biochem, 35: 49-54.

Cappuccino JC, Sherman N. 1992. Microbiology: A Laboratory Manual, New York, pp: 125-79.

Dubey RC, Maheshwari DK, Kumar H, Choure K. 2010. Assessment of diversity and plant growth promoting attributes of rhizobia isolated from Cajanus cajan L. African J. Biotechnology, 9 (50): 8619-8629. 
Geniaux E, Laguerre G, Amarge N. 1993. Comparison of geographically distant populations of Rhizobium isolated from root nodules of Phaseolus vulgaris. Mol. Ecol., 2: 295-302.

Handley BA, Hedges AJ, Beringer JE. 1998. Importance of host plants for detecting the population diversity of Rhizobium leguminosarum biovar viciae in soil. Soil Biology \& Biochemistry., 3: 241-249.

Kucuk CM, Kivanç M, Kinaci E. 2006. Characterization of Rhizobium Sp. Isolated from Bean. Turk J. Biol., 30: 127-132.

Kummerer K. 2004. Resistance in the environment. J. Antimicrob Chemoth; 45: $311-320$.

Mahana SK, Garg R, Parvateesam M. 2000. Cultural and Biochemical Characteristics of root nodule bacteria from induced mutants of Vigna mung L. Seed Pathology, Printwell publications, Jaipur, Pp: 417-421.
Martínez-Romero E. 2003. Diversity of Rhizobium-Phaseolus vulgaris symbiosis: overview and perspectives. Plant Soil., 252:11-23.

Peoples MB, Herridge DF, Ladha JK. 1995. Biological nitrogen fixation: an efficient source of nitrogen for sustainable agricultural production. Plant Soil, 174:3-28.

Somasegaran P, Hoben HJ. 1994. Handbook for Rhzobia: Methods in legume-Rhizobium technology, Springer-Verlag Publisher., New York, 450.

Sprent JI, Sprent P. 1990. Nitrogen fixing organisms. Pure and applied aspects. Chapman \& Hall, London, United Kingdom.

Virtuosic PM. 1997. Human alteration of the global nitrogen cycle: sources and consequences. Ecological Applications.,. 7: 737750 . 